\title{
Prevalence, Management And Percieved Psychological Impact Of Leprosy Disease In National Tuberculosis And Leprosy Training Centre,Saye Village,Zaria (2005-2010).
}

\author{
${ }^{1}$ B.L Ajibade (RN,Ph.D,FWACN), ${ }^{2}$ Okunlade,J.O (RN,Msc(N), \\ ${ }^{3}$ Olawale,Femi (RN,BSNc). \\ Ladoke Akintola University Of Technology, C.H.S, Osogbo 1,2 \\ Ahmadu Bello University,Dept. of Nursing,Zaria 3
}

\begin{abstract}
Abstarct: Leprosy is a medico-social problem with a declining in its medical form due to the prescence of effective treatment (MDT) but its social aspect in term of stigmatization, disability, deformities, loss of self-respect and loss of self-esteem and ostracizing of affected ones and misconception of the disease by the community have been well identified as a major threat, therefore, making patients more vulnerable to destitution and social isolation. The study was carried out to determine the prevalence,management of leprosy disease and perceived psychological impact of the disease among residents of leprosy training centre,Saye, Zaria, Kaduna State between January, 2005 and December, 2010 .The study revealed that social isolation (94\%), Anxiety $90 \%$, shame $84.4 \%$, depression $81.8 \%$, emotional disturbances $71.4 \%$, loss of self-respect, loss of self-esteem and emotional disturbances associated with disfigurement were some of psychosocial disorders. It was concluded that health education and information should be paramount when caring for the patient with leprosy because of the psychological disorders.
\end{abstract}

Key words : Prevalence, Perceived Psychological impact, Saye, leprosy

\section{Introduction}

Leprosy disease also known as Hansen's disease is a chronic granulomatous disease cause by mucobacterium leprae, an acid fast, rod-shaped bacillus principally affecting the peripheral nerve, mucosa of the respiratory tract and skin of human being (Ryan , 2004). Hansen's disease named after a physician Gerhad Armaver Hansen was discovered in 1873 and her struck fear into human being for thousands of years and known as a contagious, militating and incurable disease first recognize in the ancient civilization of China, Asia ,Latin America and Africa (Mostly Egypt) with the alarming rate is in Africa due to the sanitary environmental condition, wrong misconceptions about the disease and also over-crowded populoation (Riding -Jopling,2008). The minimum incubation period reported is as short as a few weeks and this is based on the very occassional occurence of leprosy among young infant while the maximum incubation period period reported is as long as 30 years hence it is generally agreed that the average incubation period should be put at between three and five years (American Leprosy mission 2009 ) Leprosy affected humanity for over 4000 years (Olawale,2013). World Wide, two or three million people are estimated to be permanently disabled because of leprosy with India having the greatest cases and Brazil as second followed by Burma as the third (WALSH, 2007). In 2009 the world incidence of Hansen's disease was estimate to be 640,000 in 2000, 738,284 cases were Identified (BC News, 2003). In the same year the World Health Organization listed 91 countries in which Hansen's disease is endemic with India ,Burma and Nepal containing 70\% of cases. In $2003,763,917$ new case were detected World- wide and in that year WHO listed Brazil, Madasgar,Tanzania, and Nepal as having 90\% Hansen's disease cases. According to therecent figure From which new cases are detected worlwide have decreased by approximately 107,000 cases from 2003 to 2004, in addition, the global registered prevalence of Hansen's disease was 286,063 cases, and 407,791 new cases were detected during 2004 (WHO ,2008). In Nigeria ,at the start of 1992 , WHO thought there were 360,000 people with leprosy by july , 1993, WHO had revised their estimate to 63,000 following a cleaning of the register when it was discovered that some patients had been taking treatment for 10,15 and 20 years. In 1996 appropriately 30 of past or present people affected by leprosy in Nigeria were affected with a disability or impairment. Due to the adopted multi - drug therapy in 1993 ,Nigeria achieved less than 1 care of leprosy per 10,000 people in 2003 and in 2006 Nigeria was one of the seven countries in Africa reporting more than 1,000 new cases a year, the other countries being Angola, the democratic republic of congo, Ethiopia, Madagascar , Mozambique and Tanzania . Within Nigeria leprosy which is known as "opo" in the southern part ,"Ede", in West, "Mekuturu" in the North and "Ekpenta" in the East; has the highest level of infectivity in Benue, Cross Rivers, Ebonyi and Gombe state followed closely by Adamawa,Kano,Taraba, Yobe, and 
Zamfara (WHO, 2008). The gross deformities that led to a social stigma, remain a major obstacle to self-reporting and early treatment of the disease (Joplin, 1991). It was the introduction of multi drug therapy (MDT) in the eraly 1980's that the disease could be diagnosed and treated succesfully within the community (WHO ,2006). MDT for multi - bacillary leprosy consists of srifampicin, diapsone and clofazinine taken over 12 months. Dosages adjusted appropriately for children and adult are available in all Primary Health centres in the form of blister packages (WHO , 2006) and this intervention in collaboration with leprosy mission international Nigeria (TLMN) has helped to reduce the prevalence in some regions of Nigeria where the prevalence is alarming (Awofeso , 1996). The cause of leprosy is directly linked to the bacteria mycobacterium leprae. The bacterium is thought to be spread from person to person primarily through infected droplet. However, more than half of those with the disease have no confirmed contact with an infected person. Other factors that can play a role in the cause of leprosy include genetics, the extent of exposure, and environmental conditions (Arthur, 2006).

World Wide distribution of leprosy in 2003 reveals that two to three million people are estimated to be permanently disabled because of leprosy disease with India having the highest number of cases, with Brazil as the second and Burma as third (WHO , 2003 ;Olawale 2013). In the year 2000, the WHO listed 91 countries in which leprosy disease is endemic. India, Burma and Nepal contained $70 \%$ of cases with India having over $50 \%$ of the World's leprosy cases (Times of india, 2009). 763,917 new cases were detected worldwide in the year 2002 , and in that year the WHO listed Brazil, Madasgar ,Mozambique ,Tanzania and Nepal as having $90 \%$ of the disease. According to the recent figures from WHO (2009) new cases detected has decreased by appropriately 107,000 cases (21\%) from 2003 to 2004 . This decreasing trend has been consistent for the past three years. In addition, the global registered prevalence of Hansen disease (HD) was 286,063 cases, 407,791 new cases were detected during 2004 .At the beginning of 2008, the HD stood at 212,802 cases while the number of new cases detected during 2007 was 254,525 (excluding the new cases in Europe). And about 600,000 new cases arise every year mostly in Asia, Central and South America and Pacific Island (Ryan Ray, 2004). Then leprosy mission international of Nigeria has described Benue, Cross Rivers, and Gombe State as having the highest level of disease in Nigeria folllowed by Adamawa, Kano, Taraba, Yobe and Zamfara . Leprosy has affected people for thousands of years it was and often still is, seen as a contagious mutilating disease. Today, leprosy can be clinically cured relatively easily, yet the effects is that it has on a patient's life can carry on indefinitely. It is a stigmatizing condition, and can lead to person affected being rejected and excluded from society (Kaur and Ramesh, 1994). Other examples of social exclusion are available in literature (Awofeso , 1996 ,Senturk. Sagduyu , 2004 ; Brakel , 2003 ; Bhatia, Chandra \& Bhattacharya 2006). A person's sense of well - being and the level to which they see themselves as useful is inextricably linked to their income generation and ability to secure employment for the spouse or parent, the ability to provide for dependant is linked toa sense of worth and fulfillment in their role. There are few studies on leprosy, stigma and income generation. However, some researchers have explored the topic.Kisvuli, Othieno, Mbury, Kathuku, Obon and Nasoko (2005) state that even today ,social stigmatization is frequent so that affected persons with clear signs of chronic manifestations are often unable to work, or to marry, they become dependant for care and financial loss. (Leekasa Rizuneh and Akem 2004) comment on the experience of people affected by leprosy, in their set of operational principles for rehabilitation of people affected by leprosy - pointing out that many such people live in extreme poverty and have few oppurtunities to earn an income. They may be excluded from their former work place or denied access to their former market.They went on to state that physical impact of leprosy may make it possible to continue in their former occupation. In a study on community behaviour in Eastern Nepal towards leprosy affected by leprosy experience exclusion from social life. They concluded that persons affected by leprosy experience unsympathetic reactions, insults, hate, abandonment or rejection. They went on to say that the motive for such negative community behavior is a fear of infection by germs, as well as fear of a curse of God. In a study undertaken by Peters ans Eshiet ( 2006 ), on male / female ( sex )difference in leprosy patient in south Eastern Nigeria reveals that number of thefemale case. His hospital retrospective examination shows that out of 2,309 cases, male leprosy patients were 1527 $(66 \%)$ while females were $782(33 \%)$ confirming to the usual 2:1 male / female ratio. Low ratio of female leprosy is attributed to the longer incubation period in females than males . Brakel ( 2003 ), emphasized that eliminates of leprosy disease which remain a public health risk regions, research into the transmission of M.leprae to permit new logical interventions, successful campaign and health education on leprosy disease, its prevention and control.

\section{Aims And Objectives Of The Study :-}

The broad aim of this project is to determine the prevalence and management of leprosy in national tuberculosis and leprosy training center, Saye between January, 2005 and December, 2010. 


\section{SPECIFIC OBJECTIVES :-}

- To determine the yearly prevalence of leprosy disease from January, 2005 to December , 2010.

- To determine the most prevalent type of leprosy disease in the Centre.

- To determine the geographic prevalence in the centre.

- To determine the geographic prevalence in the centre.

- To determine the psychological impact of tuberculosis among selected respondents.

- To determine the models of treatment of leprosy in the centre.

\section{RESEARCH QUESTIONS :-}

- What is the yearly prevalence of leprosy between January and December, 2010?

- Which type of leprosy is most prevalent in the centre during the study period?

- What are the perceived psychological impacts of leprosy among selected attended in the centre.

- What are the modes of treatment of leprosy disease in the centre?

\section{DELIMITATION/SCOPE OF THE STUDY}

The research is definite to National Tuberculosis and Leprosy Training Centre, Saye Village, Kaduna State between the period of 2006 and 200 . It was equally definite to the patients that were available during each visit irrespective of their sex, religions, affiliations and level of education.

\section{RESEARCH DESIGN :-}

A retrospective, and cross sectional descriptive designs were adopted for the study. The retrospective design was used to determine the prevalence and management of leprosy in National tuberculosis and leprosy training centre, Saye, while cross - sectional design was used to assess the perceived psychological impacts among respondents that were randomly selected.

\section{RESEARCH SETTING :-}

The research study was carried out in the laprosy unit in National Tuberculosis and Training Centre, Saye Village, Zaria, Kaduna state. When the North Central, Sate was created in 1963 from the old Northern region, the Zaria settlement as it was previously called was renamed the provincial leprosy settlement of the Northern Central state of Nigeria. In 1065, the government took over the ownership of the centre from the missionaries, then the name was changed to National Tuberculosis aqnd Leprosy Training Centre,Saye Village.

\section{STUDY POPULATION :-}

The study population included all medical record of leprosy patients who were diagnosed at the centre and treated between January, 2005 and December, 2010. The study extended to patient that turned up for collection of drugs.

\section{SAMPLE SIZE AND SAMPLING TECHNIQUE :-}

In this research, the data at $b$ the health record department of the centre were used. The sample size consisted of seventy seven (77) respondents that were selected randomly for a period of 5 visits. While the health records between January, 2005 and December, 2010 were used.

\section{INSTRUMENT FOR DATA COLLECTION :-}

The health records on cases of leprosy between January, 2005 and December, 2010 were used as part of the instrument while self - designed questionaire was used to assess the perceived psychological impact of leprosy. It consisted of Nine (9) items using likert type of scale.

\section{ETHICAL CONSIDERATION :-}

Ethical approval was given by the Chief Medical Director through a letter of introduction by the head of department of Nursing Science, Ahmadu Bello University, Zaria.

\section{Discussion Of Findings}

Table 1 showed the yearly prevalence of leprosy with year 2005 exprerienced highest $93 \cdot 8 \%$ Males and $06 \cdot 3 \%$ Females, follows by year 2007 with $79.7 \%$ Females. The table showed the decline in the prevalence of leprosy. The finding supports WHO, (2006, laddhan, 1997). In the year 2007 with $14.1 \%$, this report of Peter and Eshiet (2006) that out of 2,309 cases of leprosy patients $66 \%$ were Males while $33 \%$ were Females 2:1 Male / Female ratio. The finding was equally congruent with Brakel ( 2003) which emphasizes low ratio of Female leprosy. Table 2 showed that the most prevalent perceived 
psychological impact of leprosy was social isolation which was experienced by $94.8 \%$ nof respondents followed by anxiety experienced by $70(90.9 \%)$ of respondents while $65(84.4 \%), 63(81.8 \%), 55(71.4 \%)$ of respondents experienced sence of shame, depression, emotional disturbances and loss of self-respect respectively. The least experienced psychological impacts were loss of self-esteem 45(58.4) and disfigurement 45, (58.4\%). These findings were congurent with Kaur and Ramesh (1994) that leprosy is a stigmatizing condition and can lead to person being rejected and excluded from society, it also support, Awofeso(1996), that other examples of social exclusions are available in literature. The findings also support that of Senturk and Sagduyu 004; Bradel, 2003, Bhatia, et al (2006) that a person's sense of well-being and the level to which they see themselves as useful is inextricably linked to their income generation and ability to secure employment for the spouse or patients, the ability to provide foe dependants is linked to a sense of worth and fulfillment in the role. The finding on perceived psychological impact was also congruent with the finding of Kisivali et al (2005) which state that affected person with clear signs of chronic manifestation are often unable to work or to marry, they become dependant for care and financial support, leading to insecurity, shame isolation and consequently economic loss in terms of the Leekassa, R; bizuneh E \& Alem, A.(2004). Prevalence of mental distress in the outpatients clinic of a specialized leprosy hospital, Adiss Ababa, Ethiopia. Lepr Rev. 75;367-75(Pub Med) assessed 5/10/2013. Olawale, Olufemi (2013). Prevalence and management of leprosy disease in National Tuberculosis and Leprosy Training Centre, Saye Village, Zaria, January 2005 - December 2010 BNSc unpublished research, submitted to the department of Nursing, Ahmadu Bello University, Zaria. Rabbello,F.E (1980). The polar concept as it stand today. Int J. Lepr otherMyobact Dis. 48, 318- 21, (Pub Med) asssessed 11/10/2013.Ronberg, A. (1969). "Hanseniasis" the new official name for leprosy in Sao Paulo, Brazil Dermatol Int. 8, 40 - 43 (Pub Med) assessed 11/09/2013.Ryan, K.J.,m \& Ray, C.G. (00). Sherris Medical Microbiology, (4th ed). Mc Graw Hill, 451 - 3.Senturk, V., \& Sagduyu, A. (2004). Psychiatric disordered and disability among leprosy

patients. Turk psyhiati, 15;236 - 43 (Pub Med) assessed 23/09/2013.Walsh, F. (2007). The hidden suffering of India's lepers" BBC News, 31/03/2007. World Health Organisation (WHO,2006). Communicable disease department, Leprosy FAQ.

World Heath Organisation(WHO,2009). Leprosy Global Situation.

http://www.who.int/mediacetre/factssheets/fs101/enl. retrieved 30/09/2013.

\section{Results}

Table

\begin{tabular}{|l|l|}
\hline \multicolumn{2}{|c|}{ Yearly Prevalence } \\
\hline $2005-64$ & 2005 \\
\hline $2007-44$ & 2006 \\
\hline $2007-60$ & 2007 \\
\hline $2008-50$ & 2008 \\
\hline $2009-38$ & 2009 \\
\hline $2010-20$ & 2010 \\
\hline
\end{tabular}

RESULTS

Table 1a: Yearly prevalence of leprosy disease between January, 2005 and december,

2010.

2010 .

2010. 